Check for updates

Cite this: RSC Adv., 2017, 7, 51460

Received 26th September 2017 Accepted 28th October 2017

DOI: $10.1039 / \mathrm{c} 7 \mathrm{ra10656d}$

rsc.li/rsc-advances

\section{Identification of cadmium resistance and adsorption gene from Escherichia coli BL21 (DE3) $\dagger$}

\author{
Weitong Qin, \$ Xiaoqing Liu, \$Xiaoxia Yu, Xiaoyu Chu, Jian Tian (D) * and Ningfeng Wu
}

Cadmium is recognized as one of the most toxic heavy metals, and chronic cadmium exposure threatens plant, animal and human health. Because certain bacteria can play an important role in remedying heavy metal pollution, it is essential to further our understanding and clone cadmium adsorption and resistance genes from microorganisms. In this study, the cadmium resistance of different Escherichia coli strains including BL21 (DE3), JM109, DH5 $\alpha$, Top10 and Mach was determined. Among those strains, the E. coli BL21 (DE3) exhibited the highest cadmium resistance. Sequence analyses of four cadmium resistant clones screened from the BL21 (DE3) fosmid library showed that the insertion of each fosmid plasmid contained a fragment located at the lambda phage DE3 region. Next, we overexpressed several genes of this fragment in BL21 (DE3) and identified that cadmium resistance of $E$. coli is acquired through the $c a p B$ gene. Indeed, overexpression of the $c a p B$ gene increased the adsorption rate of cadmium. Taken together, these results indicated that the $c a p B$ gene confers $E$. coli BL21 (DE3) with increased cadmium resistance by adsorption of cadmium. This study provided new insight into the mechanism of microbial cadmium resistance and expanded our understanding of cadmium resistance, adsorption and bioremediation by microorganisms.

\section{Introduction}

Cadmium is a nonessential nutrient element for organisms and is regarded as one of most toxic heavy metals with an unknown biological function. ${ }^{\mathbf{1 , 2}}$ Further, as a persistent toxic substance, cadmium pollution is irreversible and especially soil pollution is of great concern in many parts of the world. ${ }^{3-6}$ Chronic cadmium exposure can not only affect the growth, yield and quality of the crops, ${ }^{7}$ but cadmium can also enter the body through the food chain and consequently endanger human health; Itai-Itai disease, respiratory and kidney disease. ${ }^{\mathbf{8} 9}$

According to previous studies, bacteria evolved several cadmium resistance mechanisms: $:^{\mathbf{1 , 2 , 1 0 - 1 2}}$ metal exclusion by a cellular permeability barrier such as the cell membrane or envelope; intracellular and extracellular sequestration through exopolysaccharide coating; ${ }^{1-3}$ reduced metal sensitivity of cellular targets and transport efflux pumps. ${ }^{13}$ Particularly the intracellular and extracellular binding of metal is of interest to researchers in the field of bioremediation as this method could be used to immobilize and adsorb target metals.

Escherichia coli, a common industrial Gram-negative bacterium and model organism, is often used in studies concerning

Biotechnology Research Institute, Chinese Academy of Agricultural Sciences, Beijing 100081, China. E-mail: tianjian@caas.cn; Tel: +86-10-82109864

$\dagger$ Electronic supplementary information (ESI) available. See DOI: 10.1039/c7ra10656d

\$ These authors contributed equally to this work. microbial remediation of cadmium pollution. ${ }^{\mathbf{1 4 - 2 1}}$ Currently, most studies focus on the overexpression of cadmium resistant genes from Gram-positive bacteria to reverse cadmium pollution or to isolate strains in heavy metal contaminated areas: ${ }^{2}$ cadA from $S$. aureus, ${ }^{22} c z c$ system from Alcaligenes eutrophus, ${ }^{23}$ and $M T S^{\mathbf{1 6 , 2 3 , 2 4}}$ and phsABC ${ }^{25}$ from Salmonella typhimurium. In fact, $E$. coli is intrinsically tolerant to high levels of cadmium up to $0.9-1.0 \mathrm{mM} \cdot{ }^{16,25,26}$ However the exact mechanism of cadmium resistance in $E$. coli is not fully understood. To date, we know that ZntA, a $\mathrm{Pb}(\mathrm{II})-$, $\mathrm{Zn}(\mathrm{II})-$, and $\mathrm{Cd}(\mathrm{II})$-transporting ATPases confer cadmium tolerance in $E$. coli.$^{\mathbf{1 3 , 1 7 - 1 9}}$ Interestingly, most cadmium resistance mechanisms currently known in microbiology are cadmium exclusion. Thus, the identification of cadmium resistant genes, especially cadmium adsorption genes, in $E$. coli would be of great importance for applications in remedying cadmium contamination.

In this study, we determined the cadmium resistance of different strains of $E$. coli including BL21 (DE3), JM109, DH5 $\alpha$, Top10, and Mach. We discovered that BL21 (DE3) had the highest cadmium resistance, up to $1.0 \mathrm{mM}$. Consequently, we constructed a BL21 (DE3) fosmid library to look for genes conferring the high resistance of $E$. coli to cadmium. Four clones with higher cadmium resistance than the wild type were identified, and the insertion fragments of the four strains were overlapped. Through overexpression of different genes in this section, we were eventually able to identify the gene related to cadmium resistance and absorption. Based on our knowledge, this is the first study to report the key gene related to cadmium 
absorption of BL21 (DE3). This work has paved the way for bioremediation and increasing cadmium resistance.

\section{Material and methods}

\subsection{Bacterial strains and growth conditions}

The plasmids and bacterial strains used in this study are listed in Table 1; EPI300-T1R came with the Fosmid Library Construct Kit. All the strains were grown in Luria Bertani (LB) medium (10 $\mathrm{g} \mathrm{L}^{-1}$ trypoton, $5 \mathrm{~g} \mathrm{~L}^{-1}$ yeast extract, $10 \mathrm{~g} \mathrm{~L}^{-1} \mathrm{NaCl}$ ) overnight at $37^{\circ} \mathrm{C}$ with shaking at $200 \mathrm{rpm}$. All reagents used in this study were purchased from Sigma-Aldrich (St. Louis, Missouri, USA).

\subsection{Determination of minimum inhibitory concentration (MIC) of cadmium}

The MIC values ${ }^{27}$ were assessed by measuring the growth rate of different strains estimated from the optical density at $600 \mathrm{~nm}$ $\left(\mathrm{OD}_{600}\right)$. For the assay, the overnight culture of the test strains was transferred into fresh LB medium and incubated at $37{ }^{\circ} \mathrm{C}$ until an $\mathrm{OD}_{600}$ of 0.6-0.8 was reached. Next, the different strains (1\%) were inoculated into 96-well plates containing different concentrations of $\mathrm{CdCl}_{2}(0-1.4 \mathrm{mM})$ in triplicate. After incubation at $37{ }^{\circ} \mathrm{C}$ for $20-24$ hours, the $\mathrm{OD}_{600}$ was measured with a fluorescence absorbance cuvette.

\subsection{Construction and screening of BL21 (DE3) genomic fosmid library}

The BL21 (DE3) total genomic DNA was extracted with the Bacterial Genome Rapid Extraction Kit (BioTeKe, China), according to the manufacturer's protocol. DNA concentration and quality were checked by absorbance cuvette $\left(A_{260} / A_{280} \sim 1.8\right)$ and gel electrophoresis (1\%). Approximately $0.5 \mu \mathrm{g} \mu \mathrm{L}^{-1}$ DNA extract was used to construct a fosmid library with the CopyControl HTP Fosmid Library Production Kit and pCC1FOS Vector (Epicentre, Madison, WI, USA), according to the manufacturer's instructions. Twelve fosmid clones were randomly selected for evaluating the insert size by BamHI digestion and agarose gel electrophoresis analysis (Fig. S1†). A total of 1443 fosmid clones (insert size range $25-40 \mathrm{~kb}$ ) were obtained and stored at $-70{ }^{\circ} \mathrm{C}$ in $40 \%$ glycerol.

To screen for clones with cadmium resistance, all fosmid clones were replicated in 96-well plates containing LB broth supplemented with chloramphenicol $\left(12.5 \mu \mathrm{g} \mathrm{mL}^{-1}\right)$ and cultivated at $37{ }^{\circ} \mathrm{C}$ for $8-12 \mathrm{~h}$. The cultures were then transferred onto solid LB medium supplemented with chloramphenicol $\left(12.5 \mu \mathrm{g} \mathrm{mL}^{-1}\right)$ containing $1.2 \mathrm{mM} \mathrm{CdCl}_{2}$ and incubated at $37^{\circ} \mathrm{C}$ for $36 \mathrm{~h}$.

Fosmid DNA was isolated from the positive fosmid clones with the High Purity Plasmid Extraction Kit (TIANGEN, China) and sequenced from both ends with an ABI 3730 DNA analyzer and the pCC1FOS vector universal primers fosmid-T7 and fosmid-RP (Table. S1†). The sequences were analyzed by BlastN (NCBI) to determine the location of the inserted fragments in the entire genome.

\subsection{Gene overexpression in E. coli}

Genes containing their promoters predicted using Web Promoter Scan Services (https:/www-bimas.cit.nih.gov/molbio/ proscan/) were amplified by PCR from the positive plasmids with the primers listed in Table S1, $\dagger$ and digested with KpnI and $X b a I$. These fragments were inserted into the $K p n I / X b a I$ double digest of pUC19-GFP, containing a reporter green fluorescent protein (GFP) gene $g f p$, to create plasmids pUC19-capA-GFP, pUC19-capB-GFP, pUC19-capJ-GFP, pUC19-regI-GFP, pUC19regII-GFP and pUC19-regIII-GFP (Table. S1 $\dagger$ ). Each plasmid was verified by DNA sequencing and transformed into $E$. coli BL21 (DE3) to express the GFP-tagged proteins CapA, CapB, CapJ, CapC, CapD, CapE, CapFi, CapFii, CapV, CapQ and CapT, respectively. All the host cells harboring the recombinant vectors were grown in $\mathrm{LB}$ at $37^{\circ} \mathrm{C}$ for $20 \mathrm{~h}$. To confirm gene expression, fluorescence of the cultures was measured with a fluorescence absorbance cuvette. Fluorescence in the wells was measured at an excitation/emission wavelength of 484/507 nm, using a microplate reader SpectraMax M2 (Molecular Devices, USA).

Table 1 The plasmids and bacterial strains used in this study

\begin{tabular}{|c|c|c|}
\hline Strains and plasmids & Description & Resources \\
\hline BL21 (DE3) & F-,ompT,hsdS(rBB-mB-),gal,dcm(DE3) & CWBIO \\
\hline $\mathrm{DH} 5 \alpha$ & 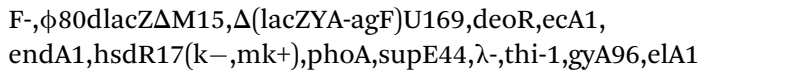 & CWBIO \\
\hline JM109 & $\begin{array}{l}\text { ecA1,endA1,gyA96,thi-1,hsdR17,supE44,elA1, } \\
\Delta(\text { lac-poAB }) \mathrm{F}^{\prime}[\operatorname{taD} 36, \text { poAB+,lacIq,lacZ } \Delta \mathrm{M} 15]\end{array}$ & CWBIO \\
\hline Top10 & $\begin{array}{l}\text { F-,mcA } \Delta(\text { m-hsdRMS-mcBC), } \phi 80, \text { lacZ } \Delta \text { M15, } \\
\Delta \text { lacx74,ecA1,aa } \Delta 139 \Delta \text { (aa-leu)7697,galU,galK,ps,(St)endA1,nupG }\end{array}$ & Our lab \\
\hline Mach & recA,tonA,endA1,hsdR, lacZ $\Delta \mathrm{M} 15$ & ThermoFisher \\
\hline BL21-pUC19-GFP & Control strain with empty pUC19-GFP plasmid & Our lab \\
\hline BL21-pUC19-capA-GFP & capA gene was overexpressed & In this study \\
\hline BL21-pUC19-capB-GFP & $c a p B$ gene was overexpressed & In this study \\
\hline BL21-pUC19-capJ-GFP & capJ gene was overexpressed & In this study \\
\hline BL21-pUC19-regI-GFP & I region was overexpressed & In this study \\
\hline BL21-pUC19-regII-GFP & II region was overexpressed & In this study \\
\hline BL21-pUC19-regIII-GFP & III region was overexpressed & In this study \\
\hline pUC19-GFP & Expression vector & Our lab \\
\hline
\end{tabular}


BL21 (DE3) cells harboring the empty pUC19-GFP expression vector were used as the negative controls.

\section{5 $\mathrm{Cd}^{2+}$ removal by protein CapB}

The $с а р B$ overexpression strains and control strains (BL21 (DE3)) with empty vector pUC19-GFP were cultivated in LB broth supplemented with ampicillin $\left(100 \mu \mathrm{g} \mathrm{mL}^{-1}\right)$ for $12 \mathrm{~h}$ in a shaking incubator $(200 \mathrm{rpm})$, before transferring them into $3 \mathrm{~mL}$ LB supplemented with $0.1 \mathrm{mM} \mathrm{Cd}^{2+}$ or $0.05 \mathrm{mM} \mathrm{Cd}^{2+}$ for $24 \mathrm{~h}$. Then the cultures were transferred into $1.5 \mathrm{~mL}$ tubes and centrifuged at $10000 \mathrm{~g}$ for $10 \mathrm{~min}$. The supernatant was separated and diluted 100 folds using $0.6 \mathrm{M} \mathrm{HCl}$ and the $\mathrm{Cd}^{2+}$ concentration was determined with an atomic absorption spectrophotometer (AAS). ${ }^{28,29}$ Based on the mean absorbance, concentration of $\mathrm{Cd}^{2+}$ was determined by comparing with mean absorbance of the standard $\mathrm{Cd}^{2+}$. The experiments were performed in triplicate.

\section{Results and discussion}

\subsection{Resistance of $E$. coli stains to $\mathrm{Cd}^{2+}$}

To determine the degree of $\mathrm{Cd}^{2+}$ resistance of $E$. coli, we examined the growth of different $E$. coli stains including BL21 (DE3), JM109, DH5 $\alpha$, Top10 and Mach in LB liquid medium with various $\mathrm{Cd}^{2+}$ concentrations. As depicted in Fig. 1a, the strain BL21 (DE3) resisted $\mathrm{Cd}^{2+}$ concentrations of up to $1.0 \mathrm{mM}$. Strain Top10 resisted up to $0.8 \mathrm{mM} \mathrm{Cd}^{2+}$ and Mach, JM109 and DH5 $\alpha$ up to $0.6 \mathrm{mM} \mathrm{Cd}^{2+}$. Clearly, from all the E. coli stains used in this study, BL21 (DE3) had the highest cadmium resistance (1.0 $\mathrm{mM} \pm$ 0.02). The evident difference between BL21 (DE3) and the other four genetically engineered $E$. coli stains is that BL21 (DE3) carries a lysogenic lambda phage DE3 that expresses T7 RNA polymerase under the control of a lacUV5 promoter. ${ }^{30}$ So we speculated that this specific DE3 sequence, located at 748 396-791 320 in the BL21 (DE3) genome, might confer the higher resistance to cadmium.

\subsection{Screening of the $\mathrm{Cd}^{2+}$ resistant DNA fragments}

To figure out the gene(s) involved in the $\mathrm{Cd}^{2+}$ resistance of BL21 (DE3), a fosmid library from genomic DNA of BL21 (DE3) was constructed in the $E$. coli strain EPI300-T1R and screened for $\mathrm{Cd}^{2+}$ resistant clones. Out of the 1443 clones, four clones (1mMCd-1, 1mMCd-2, 1mMCd-3 and 1mMCd-4) exhibited higher $\mathrm{Cd}^{2+}$ resistance than the host strain EPI300-T1R (Fig. 1b). The fosmid DNA isolated from these four clones was sequenced and by aligning the sequences with the BL21 (DE3) genome (accession number: NC_012892), we found that the inserted fragment from the four plasmids all contained a DNA fragment located between 768481 and 801476 (Table 2). Indeed, this region overlapped with the aforementioned DE3 sequence. The result confirmed that the DE3 sequence is important for the cadmium resistance of BL21 (DE3).

\subsection{Overexpression of protein CapB can improve the cadmium resistance of BL21 (DE3)}

To identify the cadmium resistant gene(s) in the DE3 sequence, we further analyzed the genetic composition and gene function of the fragment locating between 768481 and 791320 . It contained 24 genes coding for DNA packing proteins, capsid components and tail components (Fig. 2). In order to identify the target genes conferring the cadmium resistance, some of these 24 genes were overexpressed in BL21 (DE3) to see whether they could increase the cadmium resistance of BL21 (DE3). The selected genes were fusion expressed with GFP to conveniently detect the expression of target genes by measuring fluorescence. As shown in Fig. 3a, the genes capA, сарB and capJ were successfully overexpressed. However, only overexpression of capB could increase the MIC of $\mathrm{Cd}^{2+}$ for BL21 (DE3) from $1.0 \mathrm{mM}$ to $1.2 \mathrm{mM}$ (Fig. $3 \mathrm{~b}$ ). In order to confirm that the CapB

Table 2 The location of the insertion of the different plasmids in the $\mathrm{BL} 21(\mathrm{DE} 3)$ genome

\begin{tabular}{lll}
\hline & $\begin{array}{l}\text { The location of the } \\
\text { Plasmid number }\end{array}$ & \\
\hline insertion in BL21 (DE3) genome & Overlap section \\
\hline 1mMCd-1 & $768481-825247$ & $768481-801476$ \\
$1 \mathrm{mMCd}-3$ & $768435-801476$ & \\
$1 \mathrm{mMCd}-4$ & $768464-823194$ & \\
& $768403-824390$ &
\end{tabular}
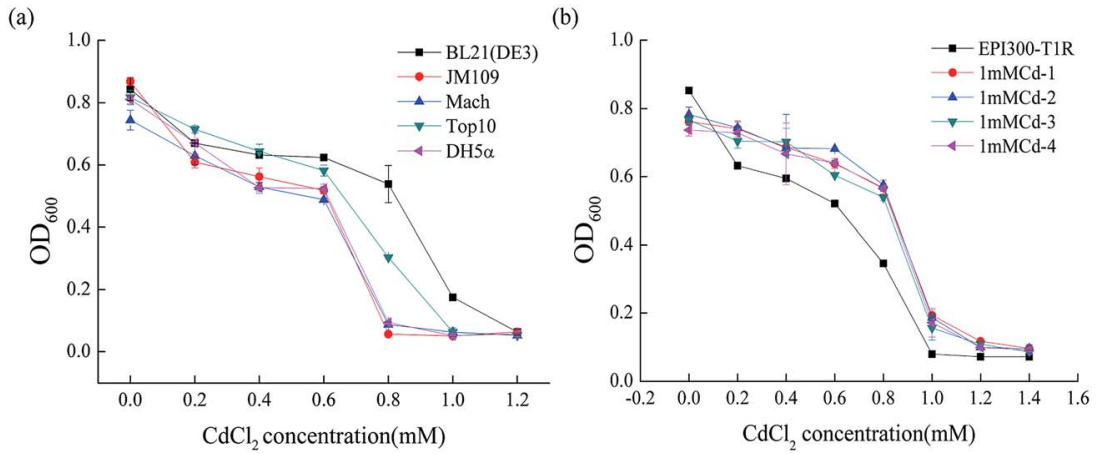

Fig. 1 (a) The minimum inhibitory concentration (MIC) of different strains of $E$. coli against cadmium. (b) The MIC of anti-cadmium strains screened in the fosmid library against cadmium. EPI300-T1R, the control strain from the Fosmid Library Production Kit; $1 \mathrm{mMCd}-1,1 \mathrm{mMCd}-2$, $1 \mathrm{mMCd}-3,1 \mathrm{mMCd}-4$ are strains screened in the fosmid library. 


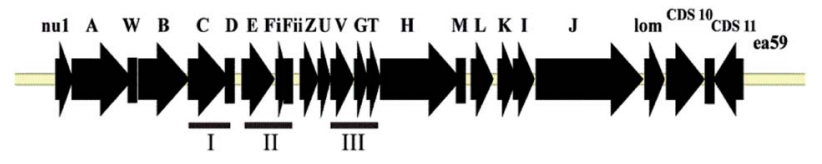

Fig. 2 The sketch map of the overlapping DE3 sequence located at 768 481-791 320. It contains 24 genes, capA is shown as A; I (regl), II (regll), III (regIII) indicate the three regions that we overexpressed.

protein is expressed under its own promoter, we also performed SDS-PAGE (Fig. S2 $\dagger$ ). In addition, overexpression of сарB in DH5 $\alpha$ was also shown to improve the $\mathrm{Cd}^{2+}$ resistance of DH5 $\alpha$ (Fig. 3c).

CapB encodes a capsid component of the lambda phage DE3 and the isoelectric point (pI) of this protein was 5.31. In the neutral $\mathrm{pH}$ environment in the cell, CapB has a negative charge that could bind to the positive ion of cadmium. Similarly, also the pIs of the proteins CapC, CapD, CapE, CapFi, CapFii, CapV, CapG and CapT were low (Table S2 $\uparrow$ ). We therefore also selected these to be overexpressed in BL21 (DE3) in the hope to identify more $\mathrm{Cd}^{2+}$ resistance related genes. Based on the promoter and position of these genes, we expressed three fragments separately: region I (containing genes $\operatorname{capC}$ and $\operatorname{capD}$ ), region II (containing genes capE, capFi and capFii) and region III (containing genes capV, capG and capT) (Fig. 2). Although the proteins were successfully expressed in BL21 (DE3) (Fig. 3a), none of the fragments changed its $\mathrm{Cd}^{2+}$ resistance (Fig. 3c). Taken together, the results suggested that the CapB protein encoded by сарв contributes to the $\mathrm{Cd}^{2+}$ resistance of $E$. coli.

\subsection{Absorption of cadmium ions by the protein CapB}

As CapB is not a membrane protein, we speculated that it may be expressed in cells to increase $\mathrm{Cd}^{2+}$ resistance by absorbing $\mathrm{Cd}^{2+}$. To verify this, the final concentration of $\mathrm{Cd}^{2+}$ was measured in culture media supernatant after cultivation of $c a p B$ overexpressing strains. We found that the $\mathrm{Cd}^{2+}$ removal rate of сарB overexpressing strains was significantly higher than the wild type BL21 (DE3) strain (Fig. 4). At $0.05 \mathrm{mM} \mathrm{Cd}^{2+}$, the $\mathrm{Cd}^{2+}$ removal rate of $c a p B$ overexpressing strains was about two-fold greater than that of the wild type BL21 (DE3). At $0.1 \mathrm{mM} \mathrm{Cd}^{2+}$, the $\mathrm{Cd}^{2+}$ removal rate of $c a p B$ overexpressing strains was also higher than that of the wild type (Fig. 4). It was speculated that such a high concentration of metal ions was toxic to cells and the gradual saturation of adsorption sites by cadmium ions would have limited the capacity of $\mathrm{Cd}^{2+}$ removal. ${ }^{31}$ The above results suggested that the $\mathrm{CapB}$ protein indeed increased cadmium resistance by absorbing more $\mathrm{Cd}^{2+}$. Unlike the earlier
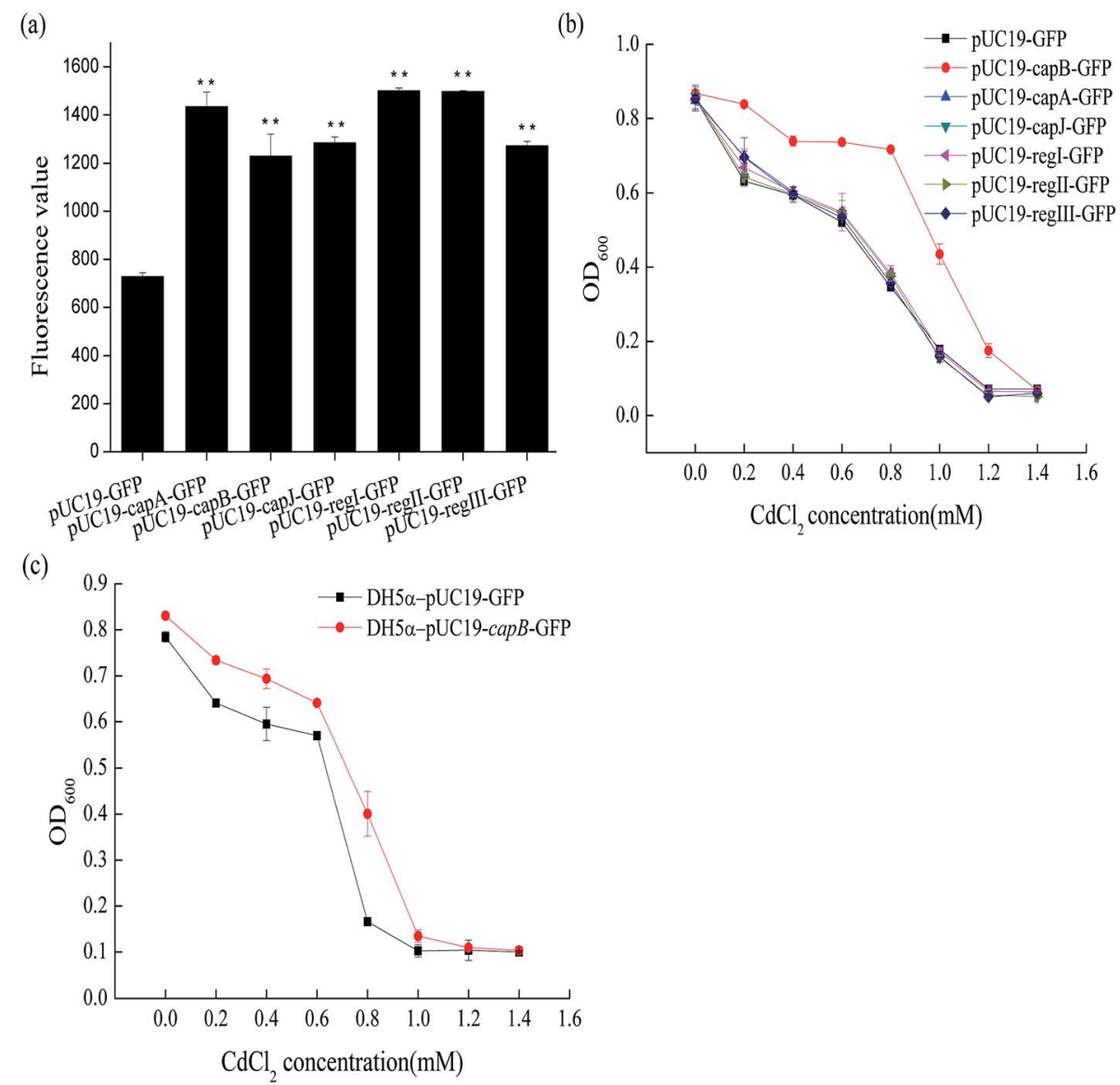

Fig. 3 (a) The fluorescence of different overexpressed genes in BL21 (DE3). pUC19-GFP is the negative control. **, $p<0.01$. (b) The cadmium MIC value of $c a p A, c a p B, c a p J$, regl, regll and reglll overexpressing recombinant strains (BL21 (DE3) as the host). BL21-pUC19is the control strain. (c) The cadmium MIC value of the capB overexpressing recombinant strain (DH5 $\alpha$ as the host). DH5 $\alpha$-pUC19 is the control strain. 


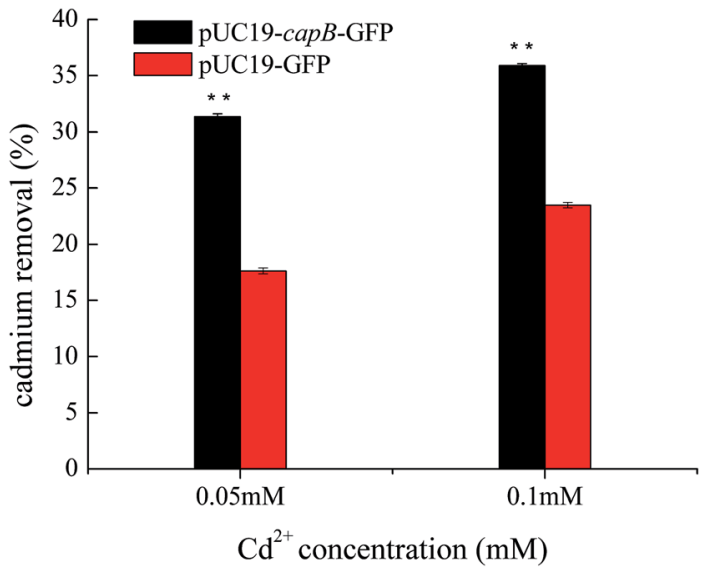

Fig. 4 Determination of cadmium adsorption capacity of recombinant strains with pUC19 as the expression vector. CapB overexpressing strains were cultivated at $0.05 \mathrm{mM}$ and $0.1 \mathrm{mM} \mathrm{Cd}^{2+}$, indicated as $0.05 \mathrm{mM}$ and $0.1 \mathrm{mM}$ respectively. pUC19-GFP was used as the control. **, $p<0.01$. Ordinate represents the cadmium removal efficiency.

discovered metallothionein, ${ }^{10,16,32,33} \mathrm{CapB}$ does not contain a lot of cysteine short peptides. The pI of CapB (5.31) was lower than the neutral $\mathrm{pH}$, implying that the protein surface will have many negative charges that can bind the positive cadmium ions in the cell. Perhaps it is just those functional negative groups that chelate with cadmium ions. ${ }^{34}$ However, a low pI is just one of the characteristics of CapB since not all proteins with a low pI could adsorb cadmium. Therefore, in addition to the low pI, the special sequence or structure is also fundamental to conferring cadmium resistance. Our future studies will thus focus on the binding characteristics of the CapB protein.

Our results reiterated that bacterial proteins could improve heavy metal resistance or adsorption. With advances in bioinformatics and the newly acquired knowledge on CapB, we may be able to improve upon the design of such proteins to remedy heavy metal pollution in the future.

\section{Conflicts of interest}

There are no conflicts to declare.

\section{Acknowledgements}

This work was supported by the National Natural Science Foundation of China (NSFC, Grant No. 31770124) and Science and Technology Innovation Project from the Chinese Academy of Agricultural Sciences (grant no. CAAS-XTCX2016018).

\section{References}

1 M. R. Bruins, S. Kapil and F. W. Oehme, Ecotoxicol. Environ. Saf., 2000, 45, 198-207.

2 Z. Khan, A. Rehman and S. Z. Hussain, Chemosphere, 2016, 159, 32-43.
3 Z. Li, Z. Ma, T. J. van der Kuijp, Z. Yuan and L. Huang, Sci. Total Environ., 2014, 468-469, 843-853.

4 G. N. Egwu and J. O. Agbenin, Arch. Agron. Soil Sci., 2013, 59, 875-887.

5 J. T. Li, J. W. Qiu, X. W. Wang, Y. Zhong, C. Y. Lan and W. S. Shu, Environ. Pollut., 2006, 143, 159-165.

6 S. Satarug, J. R. Baker, S. Urbenjapol, M. Haswell-Elkins, P. E. Reilly, D. J. Williams and M. R. Moore, Toxicol. Lett., 2003, 137, 65-83.

7 F. Villiers, V. Hugouvieux, N. Leonhardt, A. Vavasseur, C. Junot, Y. Vandenbrouck and J. Bourguignon, in Metal Toxicity in Plants: Perception, Signaling and Remediation, ed. D. Gupta and L. Sandalio, Springer, Berlin, Heidelberg, 2012, pp. 119-142.

8 K. Nogawa, M. Sakurai, M. Ishizaki, T. Kido, H. Nakagawa and Y. Suwazono, J. Appl. Toxicol., 2017, 37, 962-966.

9 S. Thijssen, J. Maringwa, C. Faes, I. Lambrichts and E. Van Kerkhove, Toxicology, 2007, 229, 145-156.

10 M. Mejare and L. Bulow, Trends Biotechnol., 2001, 19, 67-73. 11 C. Parsons, S. Lee, V. Jayeola and S. Kathariou, Appl. Environ. Microbiol., 2017, 83.

12 T. Limcharoensuk, N. Sooksawat, A. Sumarnrote, T. Awutpet, M. Kruatrachue, P. Pokethitiyook and C. Auesukaree, Ecotoxicol. Environ. Saf., 2015, 122, 322-330.

13 K. J. Tsai, C. M. Hsu and B. P. Rosen, Zool. Stud., 1997, 36, 116.

14 E. Anane, C. D. C. Lopez, P. Neubauer and M. N. C. Bournazou, Biochem. Eng. J., 2017, 125, 23-30.

15 H. Shi, Z. Z. Chen, D. Chen and J. Q. Kan, Food Control, 2017, 82, 190-195.

16 S. K. Kim, B. S. Lee, D. B. Wilson and E. K. Kim, J. Biosci. Bioeng., 2005, 99, 109-114.

17 M. R. B. Binet and R. K. Poole, FEBS Lett., 2000, 473, 67-70.

18 C. Rensing, B. Mitra and B. P. Rosen, Proc. Natl. Acad. Sci. U. S. A., 1997, 94, 14326-14331.

19 R. Sharma, C. Rensing, B. P. Rosen and B. Mitra, J. Biol. Chem., 2000, 275, 3873-3878.

20 L. Huang, Q. Wang, S. Jiang, Y. Zhou, G. Zhang and Y. Ma, Bioprocess Biosyst. Eng., 2016, 39, 1679-1687.

21 J. Tian, N. Wu, J. Li, Y. Liu, J. Guo, B. Yao and Y. Fan, Appl. Environ. Microbiol., 2007, 73, 2364-2368.

22 A. Alonso, P. Sanchez and J. L. Martinez, Antimicrob. Agents Chemother., 2000, 44, 1778-1782.

23 C. Grosse, A. Anton, T. Hoffmann, S. Franke, G. Schleuder and D. H. Nies, Arch. Microbiol., 2004, 182, 109-118.

24 E. Tokuda, E. Okawa, S. Watanabe and S. Ono, Hum. Mol. Genet., 2014, 23, 1271-1285.

25 S. W. Bang, D. S. Clark and J. D. Keasling, Biotechnol. Lett., 2000, 22, 1331-1335.

26 R. A. Laddaga and S. Silver, J. Bacteriol., 1985, 162, 11001105.

27 X. C. Chen, J. Y. Shi, Y. X. Chen, X. H. Xu, S. Y. Xu and Y. P. Wang, Can. J. Microbiol., 2006, 52, 308-316.

28 A. Vidhyaparkavi, J. Osborne and S. Babu, 3 Biotech, 2017, 7, 9.

29 Z. G. Wei, J. W. Wong, H. Y. Zhao, H. J. Zhang, H. X. Li and F. Hu, Biol. Trace Elem. Res., 2007, 118, 146-158. 
30 B. A. Moffatt, J. J. Dunn and F. W. Studier, J. Mol. Biol., 1984, 173, 265-269.

31 Z. Z. Yu, Q. F. Dang, C. S. Liu, D. S. Cha, H. F. Zhang, W. J. Zhu, Q. Q. Zhang and B. Fan, Carbohydr. Polym., 2017, 172, 28-39.
32 C. D. Klaassen, J. Liu and S. Choudhuri, Annu. Rev. Pharmacol. Toxicol., 1999, 39, 267-294.

33 C. D. Klaassen, J. Liu and B. A. Diwan, Toxicol. Appl. Pharmacol., 2009, 238, 215-220.

34 B. Liao, W. Y. Sun, N. Guo, S. L. Ding and S. J. Su, Carbohydr. Polym., 2016, 151, 20-28. 